\title{
Interacción del estudiantado y el bienestar subjetivo: análisis en un contexto escolar con diversidad étnica y cultural ${ }^{*}$
}

\author{
Fernando Lasso Paz \\ Maestro en Educación por el \\ Instituto Tecnológico de Monterrey, México. \\ Mg. en Educación por la \\ Corporación Universitaria Minuto de Dios, Colombia \\ Psicólogo por la Universidad San Buenaventura, Medellín. \\ Docente Institución Educativa las Américas, Buenaventura \\ Correo electrónico: lassopaz@yahoo.com
}

\author{
Geiler Torres Zamora \\ Esp. en Gerencia Educativa por la \\ Corporación Universitaria Minuto de Dios \\ Licenciado en Pedagogía Infantil por la Universidad del Tolima. \\ Coordinador de Educación, Arte y Cultura \\ de la Fundación Isla Cascajal FIC. Cali. \\ Correo electrónico: geilertozamora@gmail.com
}

\section{Cómo citar este artículo}

Lasso, F., Torres, G. (2015). Interacción del estudiantado y el bienestar subjetivo: análisis en un contexto escolar con diversidad étnica y cultural. Espiral. Revista de Docencia e Investigación, 5(2), 51-74.

\section{Resumen}

Este artículo de investigación hace parte del proyecto de orientación escolar de la Institución Educativa Las Américas, investigación que configura la tesis de maestría en Educación con el Instituto Tecnológico de Monterrey y UNIMINUTO.

Tiene como objetivo, comprender cómo son las formas de interacción de los y las estudiantes de la mencionada institución y su influencia en el bienestar subjetivo, en un contexto escolar con diversidad étnica y cultural, así mismo se identificaron algunas alternativas con que cuenta la institución educativa donde se desarrolla la investigación, para garantizar el bienestar subjetivo del estudiantado, que se relaciona en contexto de diversidad cultural. El estudio se desarrolló a través del método cualitativo de corte fenomenológico, como instrumentos de investigación se utilizaron la entrevista semiestructural, que se aplicó a 20 estudiantes de diversas etnias, y la observación directa, como métodos para fortalecer la información recolectada. A partir de los resultados se pudo concluir que la diversidad étnica y cultural es un factor que determina las formas de interacción del estudiantado así como también, influencia el estado de bienestar subjetivo de este.

Palabas clave: identidad cultural, diversidad cultural, interculturalidad, interacción social, bienestar pedagógico.

\begin{abstract}
This research article is a part of school counseling project of Las Americas School. The research forms the Master's thesis in Education with the Technological Institute of Monterrey and UNIMINUTO.

It aims to understand the ways of interaction of the students of that institution and its influence on subjective welfare, in a school context with ethnic and cultural diversity. Moreover, some available alternatives in the educational institution were identified available to ensure the student subjective welfare, which are related in the cultural diversity context.

The study was conducted through qualitative phenomenological method. The semi structured interview was applied as a research instrument to a sample of twenty (20) students from different ethnic groups, as well as direct observation, as methods to strengthen the information collected. From the results, it was possible to conclude that ethnic and cultural diversity are factors that determine the students' interactions and also influence its subjective welfare state.
\end{abstract}

Keywords: cultural identity, cultural diversity, multiculturalism, social interaction, educational welfare.

\footnotetext{
Artículo de investigación que hace parte del proyecto de orientación escolar de la Institución Educativa Las Américas. La investigación configura la tesis de maestría en Educación con el Instituto Tecnológico de Monterrey y UNIMINUTO.
} 


\section{Introducción}

La transformación de la educación es una tarea sinérgica que trasciende las fronteras del compromiso y la responsabilidad que esta requiere como derecho y como servicio público. En este sentido, desarrollar una educación que responda a las exigencias del siglo XXI, con todos sus cambios sociales, económicos, culturales y tecnológicos; es una situación que la escuela debe comprender, puesto que, desde su labor educativa, está en la obligación de incidir en la construcción de los lineamientos que van determinando el futuro y el tipo de educación que debe recibir el ser humano que vive en la actual sociedad.

Se puede constatar que uno de los desafíos que tiene la escuela en la actual época, es poder desarrollar una educación que propicie la aceptación, cultivo y respeto por la diferencia, desde una perspectiva dialógica que permita la identificación de convergencias para construir sociedad, independientemente de las divergencias de cultura, etnia, condición sexual, género, cosmovisión, entre otras.

En este sentido, el presente artículo se inscribe como un aporte a las diferentes dinámicas pedagógicas, que deben desarrollarse en contextos educativos caracterizados por la diversidad étnica y cultural. Así mismo, es una contribución a las diferentes estrategias y métodos utilizados para evaluar el estado de bienestar del sujeto, aspecto que está determinado por las dinámicas propias de cada contexto. De esta manera, se considera que este estudio contribuye a los fines de la educación, puesto que se interesa por una problemática específica, que hace parte de los desafíos que presenta la educación actual.

En este orden de ideas, se desarrolla en el artículo, un análisis sobre la forma como los y las estudiantes interactúan dentro del contexto escolar, ya que, de acuerdo con las diferentes posiciones teóricas la integración está determina por diversos factores que le darán una característica a la forma particular como el sujeto se relaciona. En este sentido, se considera la diversidad cultural como un elemento que determina significativamente las formas de interacción, puesto que entenderla supone reconocer la existencia de diversas formas de concebir el mundo, desde unas realidades culturales con unas características propias. De este modo, desde el abordaje metodológico se propone identificar qué elementos, producto de este análisis, afectan de forma positiva o negativa el bienestar subjetivo, es decir, se pretende dar cuenta de los aspectos cognitivos, afectivos, y las conclusiones que establecen los y las estudiantes que viven en constante interacción con sus pares procedentes de diversas etnias y culturas; así como también, el reconocimiento e identificación de las estrategias que la escuela como contextos de interacción intercultural desarrolla para garantizar los más altos índices de bienestar a nivel subjetivo y a nivel pedagógico. En este orden de ideas, los resultados y conclusiones que se presentan permiten nutrir la creencia de que la diversidad étnica y cultural es una condición del ambiente escolar que determina las formas de internación y afecta positiva o negativamente el bienestar; por tanto, es tarea de las instituciones propiciar altos niveles de bienestar, teniendo en cuenta que este es un elemento indispensable en cualquier forma de interacción humana.

\section{Perspectivas teóricas}

\section{La interacción desde la perspectiva teórica de los estudios sociológicos}

Inicialmente, es importante caracterizar las formas de interacción entre los sujetos en el contexto que se sitúa nuestra investigación. Por consiguiente, exponemos algunas alternativas de análisis que brinda la teoría sociológica de la interacción social.

De acuerdo con esta teoría, se debe tener en cuenta que el fenómeno de la interacción social, independientemente del contexto en el que este se desarrolle, está determinada por al- 


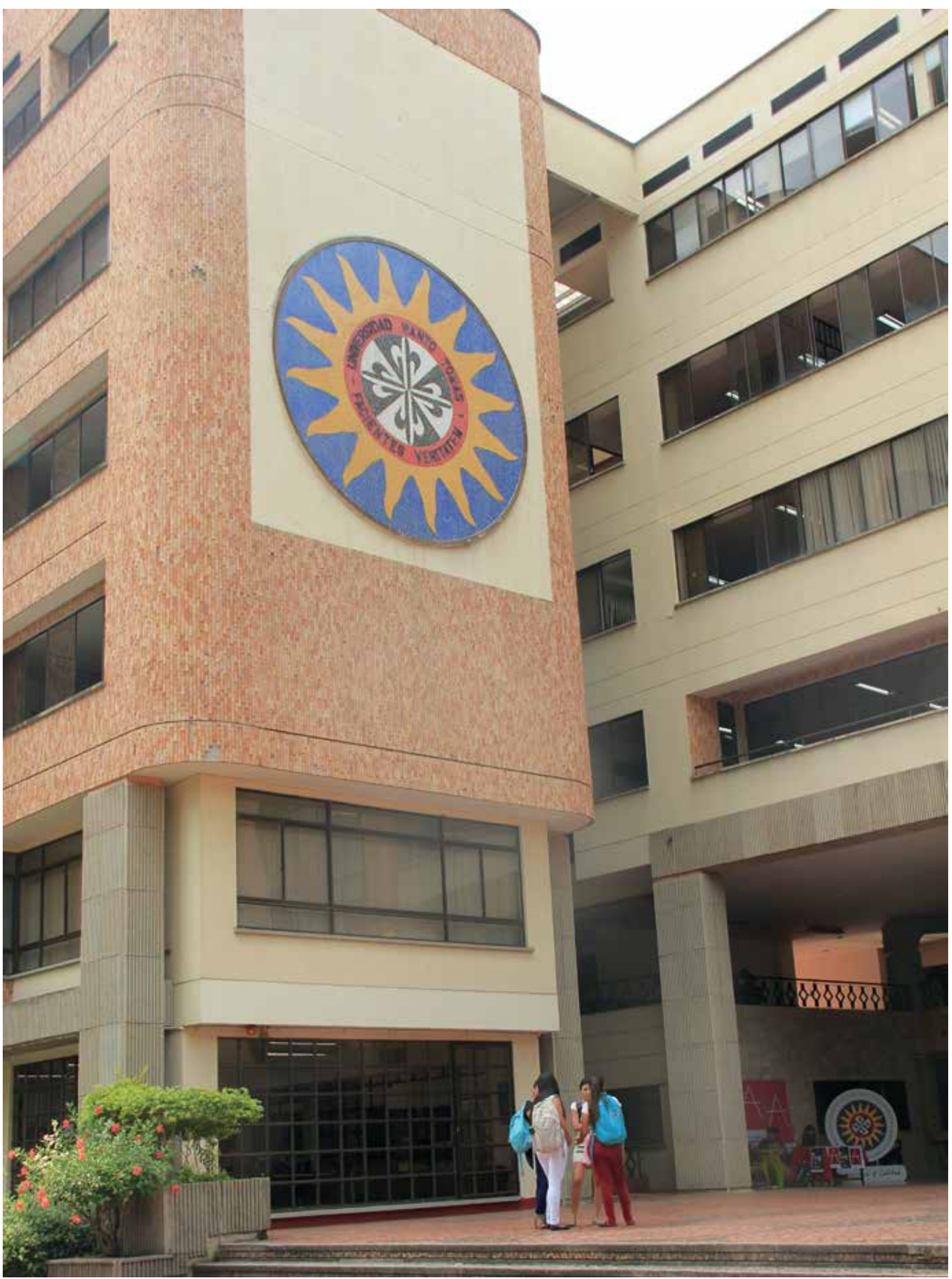


gunos factores que le dan el tinte característico a estas formas de interacción; que se constituyen en un elemento fundamental para el desarrollo del ser humano, en conjunción con el orden cultural y social al que pertenezca (Pino \& Alfonso, 2011).

En ese sentido, Pino Bermúdez et al. (2011) en su trabajo Las teorías de la interacción social en los estudios sociológicos, exponen la posición teórica de algunos autores frente al fenómeno de la interacción social.

En este estudio, Ritzer (2007) citado por Pino \& Alfonso (2011) expone que Durkheim construye una de las ideas fundamentales acerca de la interacción, puesto que afirma que "los cambios en el nivel de los macrofenómenos sociales producen cambios en el nivel de la acción y la interacción individual". La teoría de Durkheim está basada en la idea de que los hechos sociales tienen un carácter material e inmaterial, enfatizándose sus estudios en la socialización.

Por otra parte, se afirma que la comprensión de la interacción entre la gente, es una de las grandes tareas de la sociología. Georg Simmel le imprime un carácter psicológico, haciendo énfasis en los modos de interacción. Este autor se preocupa principalmente por el nivel interaccional de la realidad, añadiendo que las interacciones pueden ser momentáneas o permanentes, conscientes o inconscientes, superficiales o profundas y que mantienen constantemente el vínculo entre los hombres (Pino \& Alfonso, 2011).

De este modo, al comparar las dos posturas teóricas, se puede evidenciar que en la primera el autor hace énfasis en considerar que las interacciones de las personas están más determinadas por factores externos a nivel macro que "decretan" las formas y modos como los sujetos se relacionan en contextos específicos. Paralelo a ello, la segunda postura no tiene muy en cuenta los hechos sociales a nivel macro, sino que considera que la sociedad es una síntesis de todas las interacciones específicas, es decir, una sumatoria de la relación entre los sujetos; en este sentido, la realidad (contenido) se expresa de múltiples maneras por las personas (actores), lo que permite entender la interacción como un número ilimitado de forma de expresar la realidad que poseen unas características comunes.

La interacción no constituye un conjunto confuso de acontecimientos específicos sino las disímiles formas en que estas se llevan a cabo. Esta metodología de análisis permite por lo general, según Simmel (1959), obtener un estrato de las características comunes que se encuentran en un amplio frente de interacciones específicas. Por ejemplo, las formas interactivas de supraordenación y subordinación se basan en una vasta gama de relaciones, tanto en el estado, como en una comunidad religiosa, (...) tanto en una escuela como en una familia (Ritzer, 2007 citado por Bermúdez y Gallego, 2011).

Otro pensamiento importante sobre las forma de interacción es el de Mead, quien con su teoría de los símbolos significantes, explica que existen unos gestos que surgen y pueden generar una comunicación entre individuos. Para Mead, las formas vocales que tienen más posibilidades de convertirse en un símbolo significante es el lenguaje, estas ideas son las que posteriormente le dan origen a las posturas teóricas de Blumer, sobre el "interaccionismo simbólico", el cual se basa en la idea de que las personas interaccionan entre sí, no solo con sus gestos sino también con símbolos, constituyéndose así en formas de interacciones más complejas. El interaccionismo simbólico aporta importantes ideas a la teoría de interacción social, de las que se destacan las siguientes:

- La capacidad de pensamiento de los seres humanos, está modelada por la interacción social.

- En la interacción social las personas aprenden los significados y los símbolos que les permiten ejercer su capacidad de pensamiento. 
- Los significados y los símbolos permiten a las personas interactuar de una manera distintiva.

- Las personas son capaces de modificar o alterar los significados y los símbolos que usan en la acción y la interacción sobre la base de su interpretación de la situación.

- Las pautas entretejidas de acción e interacción constituyen los grupos y las sociedades.

Finalmente, Parsons, con su teoría del funcionalismo estructural, relacionó a la interacción con el sistema social, que definió como:

...un sistema social consiste en una pluralidad de actores individuales que interactúan entre sí en una situación que tiene, al menos, un aspecto físico o de medio ambiente, actores motivados, (...) y cuyas relaciones con sus situaciones -incluyendo a los demás actores- están mediadas y compartidas por un sistema de símbolos culturalmente estructurados y compartidos (Ritzer, 2008 citado por Pino y Alfonso, 2011).

Entendido de este modo, el sistema social es todo tipo de colectividad donde un conjunto de individuos interactúan y pueden satisfacer sus necesidades individuales y colectivas. Sin embargo, Parsons no toma la interacción como una unidad importante en sus hallazgos, ya que el concepto de sistema social se relaciona con la concepción de sistema social como un sistema de interacción. En este sentido, a través del esquema AGIL, el cual es el núcleo de la obra de Parsons, se definen cuatro sistemas de la acción, que se convierten en herramientas determinantes en el análisis de la realidad, desde esta perspectiva. Estos sistemas son los siguientes: sistema de la acción, sistema social, sistema cultural y sistema de la personalidad.

A partir de estos postulados teóricos podemos concebir la escuela como un contexto de interacción susceptible al análisis. Vale la pena resaltar que los sujetos que interactúan en la escuela obedecen regularmente a formas culturales diversas, las cuales encuentran puntos de divergencia y convergencia que determinan las formas de interacción. Estas formas de interactuar o relacionarse pueden caracterizarse por ser armónicas, puesto que los actores consiguen desde su individualidad establecer formas de comunicación adecuadas que propenden por el bienestar mutuo, o en su defecto, que atentan contra la integridad de las personas en interacción.

\section{El bienestar pedagógico: ¿qué incide en él y cómo se puede estudiar?}

El bienestar en el contacto entre los sujetos, visto desde diversas perspectivas, es un elemento indispensable en cualquier forma de relación o interacción humana; esto lo convierte en una categoría de análisis importante, puesto que las personas regularmente tienen formas de actuar inconscientes o razonables que van en contravía de este estado necesario para la armonía de la vida individual y colectiva de las personas.

Por lo tanto, en contextos escolares, más aún, cuando estos tienden a contener comunidades estudiantiles tan diversas, resulta indispensable analizar los estados de bienestar. La escuela debe promover una educación que garantice el bienestar de todos y todas, independientemente de sus diferencias. En relación con lo anterior Hirmas (2008) retoma lo siguiente:

Las diferencias son inherentes a los seres humanos, siendo una muy principal la diferencia que emana de la procedencia cultural, sustento dinámico y cambiante desde el cual el sujeto construye su identidad propia. La respuesta de la educación a la diversidad implica asegurar el derecho a la identidad propia, respetando a cada uno como es, con sus características biológicas, sociales, culturales y de personalidad, que permiten precisamente la individualización de un sujeto en la sociedad (Unesco, 2007).

Hasta ahora, los estudios sobre el bienestar han demostrado que este es susceptible a 
los del contexto. Konu et al. (2002) citados por De Pablos (2012) atañe que el bienestar está influenciado por las relaciones sociales que se desarrollan en la escuela: el clima de la escuela, la dinamicidad de los grupos, la relación entre profesores y estudiantes, las posibles situaciones de acoso, la cooperación con las familias, la convivencia, entre otras.

Entonces, la escuela debe identificar si las condiciones del contexto generan en primera medida una problemática de conflicto entre sus diferentes actores, creando malestar entre sí; o, en segunda instancia, es un componente importante en el establecimiento de las relaciones que permite promover el bienestar de los sujetos en interacción.

Con respecto a las formas de estudiar el bienestar, Díaz (2011) citado por De Pablos y Pérez (2012) señala los constructos más comunes que se emplean para su medición en diferentes contextos. En cuanto al análisis en contextos escolares, el bienestar subjetivo de los estudiantes posee gran relevancia, así como también el bienestar pedagógico (De Pablos, 2012).

El bienestar subjetivo según Diener, Suh, Lucas y Smith (1999) citado por Cuadra y Florenzano (2003) se refiere a lo que las personas piensan y sienten acerca de sus vidas, y a las conclusiones cognoscitivas y afectivas que ellos alcanzan cuando evalúan su existencia y el bienestar pedagógico, según De Pablo (2012) se puede entender como la valoración cognitiva y emocional del profesorado, en la que la felicidad, la sensación de plenitud, la autoestima, la motivación y la satisfacción por su trabajo son algunas cuestiones que pueden influir notablemente en los niveles de bienestar del profesorado y el alumnado.

El análisis del bienestar subjetivo tiene su origen en la psicología positivista, la cual surge con el objetivo de investigar acerca de las fortalezas y virtudes humanas y los efectos que estas tienen en las vidas de las personas y en las sociedades en que viven (Cuadra y Florenzano, 2003). Para medir el bienestar subjetivo, los diferentes investigadores han implementado metodologías basadas en escalas de los diferentes contextos. De acuerdo con De Pablos (2012) es importante conocer algunas de las escalas que asocian el bienestar subjetivo con factores claves como la satisfacción, la alegría, el placer, la autoestima, la forma de pensar, los valores, las emociones, la resolución de problemas, y cómo esta visión se puede ver reflejada en los entornos de enseñanza-aprendizaje.

De este modo, se abordará la interacción y el análisis del bienestar subjetivo en los contextos escolares, caracterizados por la diversidad cultural. Así mismo, se intentará analizar las estrategias con que cuenta la escuela para hacer frente a los retos que le plantean este tipo de contextos.

\section{La diversidad cultural, la escuela y la educación}

En cualquier contexto social, la cultura de origen y otros factores como la diferencia de género, la posición social, la divergencia de pensamiento, entre otros, determinan el modo de interacción entre los sujetos que conviven en un mismo lugar. En este escenario, la escuela del siglo XXI tiene una responsabilidad inmensa frente a esta condición, puesto que, la diversidad étnica y cultural, es un elemento que coexiste con el resto de características que se pueden considerar inherentes, no solo del ser humano, sino que también, de los contextos donde este interactúa.

Vivimos en un mundo donde la diversidad cultural es la regla. La diversidad es la norma. La diversidad es un hecho de la vida. Aislarse o defenderse de esta diversidad, vivida como contaminación y conflicto o, por el contrario, respetar, aceptar y convivir con la misma es la polémica y la dificultad en la que se debaten actualmente muchas sociedades desarrolladas (Sáez, 2006).

En consecuencia, los centros escolares deben reconocer y revelar la importancia de las 


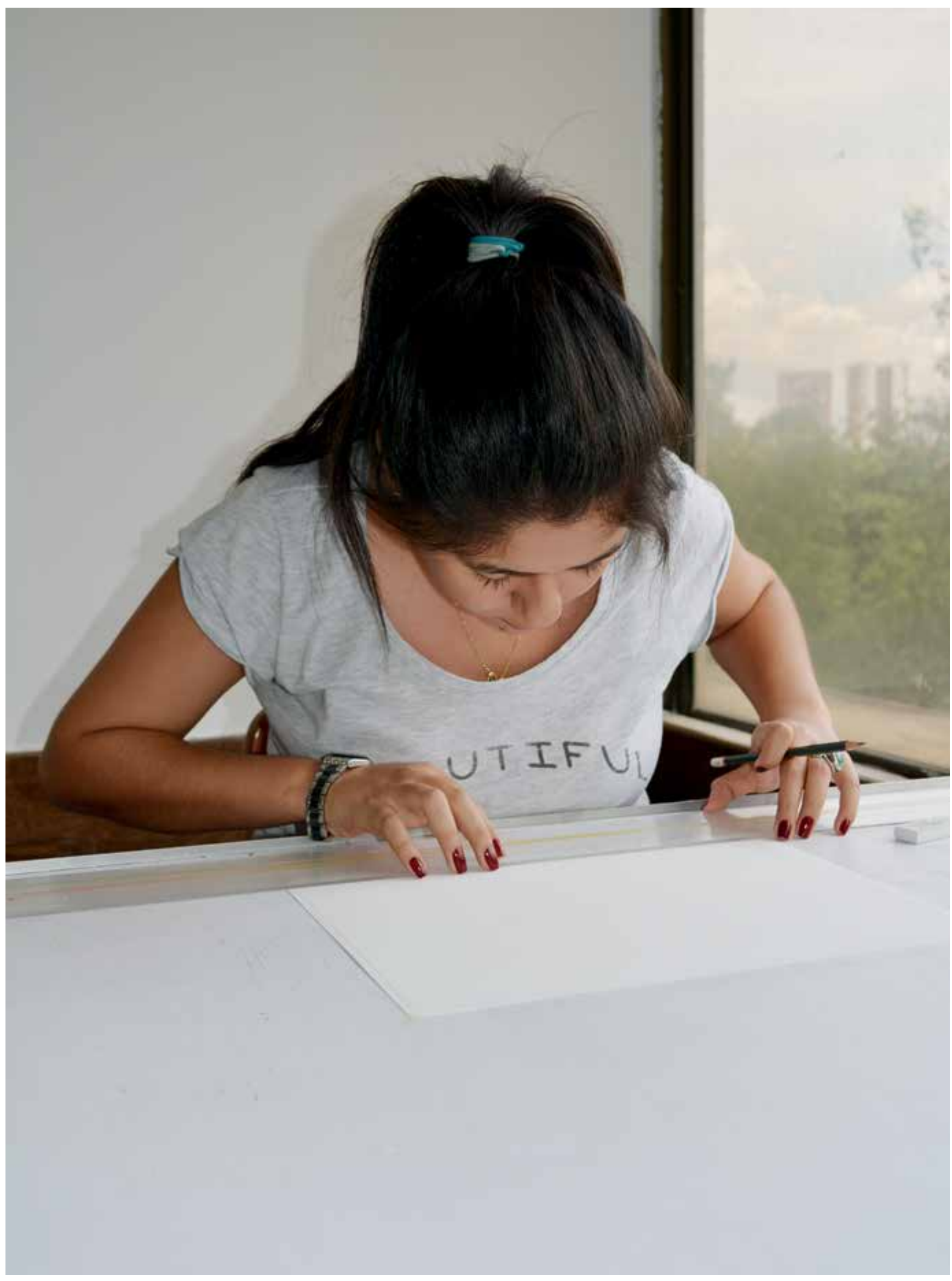


diferentes formas culturales con sus ritmos, estilos y procesos propios. Puesto que, de acuerdo con Hirmas (2008)

la diversidad cultural impone a la educación la doble misión de alentar una toma de conciencia de la igualdad del valor de las culturas (la ausencia de jerarquía o superioridad entre culturas) y del valor positivo de las diferencias. El contacto cultural no debería entenderse como contaminación, amenaza, deterioro o invasión, sino como enriquecimiento y oportunidad.

Lo anterior implica comprender la cultura de tal forma que se puedan establecer fuentes de comunicación entre culturas que propicien este tipo de dinámicas y que favorezcan los pilares de la educación, expuesto en el informe "La educación encierra un tesoro". Informe presentado a la Unesco de la Comisión Internacional sobre la Educación para el Siglo XXI (Delors, 1997, como se cita en Sáez, 2006):

- Aprender a conocer lo que significa adquirir el dominio de los instrumentos mismos del saber para descubrir y comprender el mundo que nos rodea.

- Aprender a hacer es privilegiar la competencia personal e incrementar niveles de calidad.

- Aprender a vivir juntos es habilitar al individuo para vivir en contextos de diversidad e igualdad, tomando conciencia de las semejanzas y de la interdependencia entre los seres humanos.

- Aprender a ser significa aprender a desarrollarse como persona, global y armónicamente. (Sáez, 2006).

En este orden de ideas, Sáez (2006) presenta dos definiciones de cultura interesantes para comprender el dinamismo de este concepto, la primera hecha por Jordán (1997) quien describe: "la cultura es un conjunto de significados que dan sentido o filtran la forma de entender la realidad física, social y espiritual en la que se inserta" y la segunda por Camillero, quien construye una definición más formal.

La cultura es el conjunto de significaciones persistentes y compartidas, adquiridas mediante la filiación a un grupo social concreto, que llevan a interpretar los estímulos del entorno según actitudes, representaciones y comportamientos valorados por esa comunidad: significados que tienden a proyectarse en producciones y conductas coherentes con ellos (Sáez, 2006).

También, se entiende la cultura, como "ese todo complejo que incluye el conocimiento, las creencias, el arte, la norma, el derecho, la costumbre y cualquier otro hábito y capacidades adquiridas por el hombre como miembro de la sociedad" (Kottak). Definición que se centra en las creencias y comportamientos que la gente adquiere, no a través de la herencia biológica, sino por desarrollarse en una sociedad concreta donde se hallan expuestos a una tradición cultural específica.

Es así como la cultura abarca todo, incluye mucho más que refinamiento, gusto, satisfacción, educación y apreciación de las bellas artes; abarca características que, a veces, son vistas como triviales o no merecedoras de un estudio serio. A su vez, la cultura es simbólica, verbal o no verbal dentro de un lenguaje particular.

Con estas definiciones puede acercarse, entonces, al concepto de identidad cultural, el cual se puede asimilar comprendiendo la noción de "conciencia cultural" de Anthony P. Cohen, quien según Flores (2005), a lo largo de su texto Belonging: The experience of culture (1982) maneja el concepto para entender el sentido de la diferencia de los individuos entre ellos mismos y hacia los extraños o ajenos a su comunidad, lo que constituye la base de formación de las identidades.

Así mismo, la identidad cultural implica los términos de comunión con unos y exclusión de otros, y esto se materializa en planos concretos 
de la vida social, como lo son el territorio, la historia, el lenguaje, la religión, los patrones estéticos, entre otros.

De este modo, se puede entender la identidad como la capacidad de reconocer límites y fronteras de lo que existe. Comportamientos que no pertenecen a nuestras normas y valores, y que, por lo tanto, "somos nosotros mismos" precisamente porque no somos "Ios otros" (Flórez, 2005).

En definitiva, la identidad cultural se puede entender como la multiplicidad de formas en que se expresan las culturas de los grupos y sociedades. Estas expresiones se transmiten dentro y entre los grupos y las sociedades (Unesco, 2001).

En este orden de ideas, la escuela como contexto de múltiples identidades tiene la tarea de poner en diálogo todas estas particularidades, de tal manera que se puedan generar posibilidades de compartir expresiones culturales dentro de una dinámica de bienestar que propenda por garantizar el derecho a la identidad propia y el respecto por las diferencias.

Para ello, Hirmas (2008) afirma que para que la escuela pueda abordar la condición de diversidad cultural se debe privilegiar estos vectores, que son: la pertinencia, la convivencia y la inclusión.

En cuanto a la pertinencia, en primera instancia, los contenidos deben tener una lógica de tal modo que se generen aprendizajes significativos, en segundo lugar, que en la estructura cognitiva del alumno existan elementos que se puedan relacionar con dicho material, es decir, que tengan significatividad psicológica (Coll, 2004) citado por (Hirmas, 2008). De esta manera se contribuye a que los estudiantes, sus familias y comunidad reconozcan el valor de los conocimientos que adquieren en la escuela. Esto implica una pedagogía adecuada a los niveles de competencia de cada alumno y que tomen como punto de partida sus concepciones de mundo de origen (Hirmas, 2008).

Con respecto a la convivencia se hace énfasis en el análisis de las formas de interacción más directamente. En palabras de Hirmas (2008):

El segundo vector se relaciona con el estudio de las formas de convivencia, esto es, la formación de actitudes, valores y comportamientos, ya sea de aceptación o rechazo, de entendimiento o confrontación, de colaboración o exclusión, de respeto a la legitimidad del otro o intolerancia.

En este sentido, es importante que se busque que la sociedad en general y en nuestro caso los estudiantes puedan respetar la singularidad del otro, valorando positivamente la diferencia. De acuerdo con Blanco (2005)

La valoración negativa de las diferencias y los estereotipos conducen a la exclusión y la discriminación [...] En este sentido, se podría decir que la educación tiene una deuda pendiente con el respeto de las múltiples identidades y opciones personales, dada la uniformidad de la respuesta educativa que caracteriza a los sistemas educacionales (Blanco, 2005 citado por Hirmas, 2008).

Con respecto a la inclusión, esta debe considerarse como un compromiso. La escuela debe estar en disposición para construir análisis crítico, mejorar los aprendizajes y la participación del estudiantado dentro y fuera de la institución, minimizando en lo más posible los índices de desigualdad, así generar las mismas oportunidades para el ingreso y la permanencia, independientemente de las condiciones culturales o sociales.

Se trata de que tanto la persona como la sociedad asuman las características singulares de cada ser humano y se valoren positivamente dichas diferencias, ya que éstas nos enriquecen. La valoración negativa de las diferencias y los estereotipos conducen a la exclusión y la discriminación [...] En este sentido, se podría decir que la educación tiene una deuda pendiente con el respeto de las múltiples identidades y opciones personales, dada la uniformidad de la respuesta 
educativa que caracteriza a los sistemas educacionales (Blanco, 2005 citado por Hirmas, 2008).

Se puede constatar que la inclusión es una de las mejores alternativas para afrontar la desigualdad social, muchas veces causada por la imposición de jerarquía o por complejos de superioridad entre culturas. Las mal Ilamadas "minorías" las poblaciones indígenas, afrodescendientes, migrantes, desplazados, entre otras, son los que regularmente viven en condiciones de pobreza extrema. Aspecto que es una tarea de la educación. Con frecuencia se argumenta que la educación ha de ayudar a reducir la pobreza y las desigualdades, promover la movilidad social, y mejorar las condiciones de vida de las personas y de las sociedades (Hirmas, 2008).

En este sentido, poder responder a lo anterior es pensar al mismo tiempo en una educación intercultural, así "la interculturalidad en la educación debe asumirse como algo más normativo, que garantice el derecho a una educación que reflexione sobre las condiciones que la hacen inviable en la práctica, revisar las raíces de las desigualdades sociales en el acceso a recursos materiales y simbólicos y de una propuesta para superar estas desigualdades" (Fuller, 2002 en Zavala et al., 2005) citado por (Hirmas, 2008).

La educación intercultural se debe ocupar de atender las desigualdades en el interior de la institución educativa y abordarse así de la misma manera como se aborda cualquier situación de enseñanza aprendizaje o del rendimiento escolar.

Es así como se llevan a cabo políticas de discriminación positiva hacia las minorías culturales, para compensar las desigualdades sociales con que estos grupos ingresan al sistema. Visto desde el enfoque intercultural, estas políticas conviene que sean, además, adecuadas a las culturas. Así, las situaciones de analfabetismo, ausentismo, reprobación, deserción y los bajos niveles de aprendizaje, originadas en la mar- ginación y exclusión social de esta población, facilitan la inclusión con arraigo (Hirmas, 2008).

Finalmente, teniendo en cuenta lo anterior, la educación intercultural debe concebirse como una práctica que promueva el derecho a la identidad propia, incluye la diversidad cultural desde una perspectiva de respeto y equidad social, en aras de aportar al desarrollo, crecimiento, transformación y liberación de las potencialidades humanas (Walsh, 2005).

De lo anterior, se derivan dos problemas relevantes en la presente investigación; el primero referido al análisis de las formas de interacción de los estudiantes con diversidad étnica y cultural en contextos escolares, paralelas al bienestar subjetivo como elemento indispensable en el establecimiento de las relaciones y el auto-reconocimiento de las cualidades propias que permiten incluso reconocer al otro. En el segundo se interpela por las alternativas de la escuela frente a las necesidades que surgen a partir de la interacción de los estudiantes, debido a que la escuela debe cumplir un papel importante, en la promoción del bienestar de la comunidad educativa.

Desde este punto de vista, la presente investigación hará un gran aporte al tema de las relaciones interpersonales, el respeto a la diferencia, la educación intercultural, la inclusión y el bienestar en el interior de la institución educativa; del mismo modo, es una contribución a la construcción de la paz, debido a que desde este análisis se puede contribuir a la reflexión sobre cómo pensar y abordar situaciones de injusticia, violencias, discriminaciones y exclusiones producidas regularmente por el malestar de las relaciones que se institucionalizan dentro de las instituciones educativas y que marginan a gran parte de la humanidad, en beneficio de unos pocos.

\section{Antecedentes investigativos}

En la práctica educativa se presentan un sin número de situaciones que en ocasiones pue- 
den favorecer o alterar el bienestar de los estudiantes, aspectos que deben ser atendidos por la comunidad académica, de modo que, el alumnado pueda contar con ambientes favorables para el normal desarrollo de sus actividades formativas. En relación con lo anterior, la investigación pedagógica ha concluido que el bienestar es un aspecto susceptible a las diferentes condiciones que presentan los contextos escolares en la actualidad. Con respecto a la condición de diversidad étnica y cultural y su incidencia en el bienestar, se han encontrado algunas investigaciones relacionadas con el tema en cuestión, lo que permite reafirmar la relevancia académica de la presente investigación.

Por su parte, Aguado (2005) de la Universidad Nacional de Educación a Distancia, a través de un proceso de investigación documental, hizo una revisión de investigaciones que se han realizado en el ámbito escolar español, en los últimos veinte años, acerca de la educa- ción intercultural en la práctica escolar, donde propone que la educación intercultural, como una práctica educativa, sitúe las diferencias de individuos o grupos como foco de reflexión e investigación educativa, concluyendo que la diversidad cultural propia de una sociedad democrática, debe valorarse desde el pluralismo cultural como riqueza y recurso educativo.

Del mismo modo, Castro (2009) publicó su artículo en la Revista Digital de Historia y Arqueología desde el Caribe, el cual es un balance del estado del arte, de las perspectivas que ha abordado la educación intercultural en Colombia. El documento hace un recorrido por los diversos estudios que sobre diversidad cultural se han realizado en este país, desde diferentes tendencias conceptuales y disciplinares de la diversidad cultural, abordando las tendencias pedagógicas de moda en relación con la diversidad cultural y las desigualdades sociales, entrecruzando la diversidad cultural con la

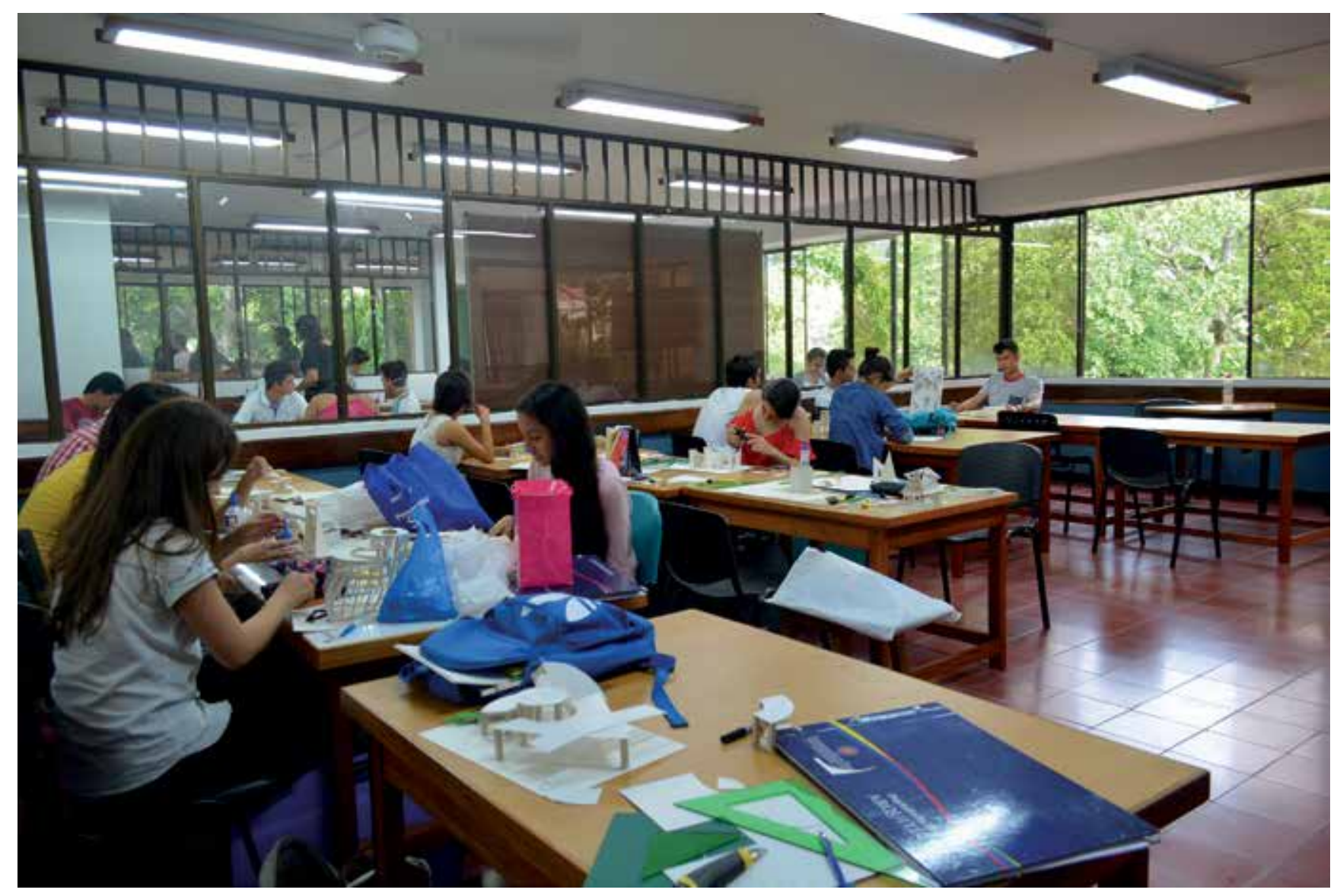


educación, entre otras, reconociendo la importancia de esta en la construcción de la sociedad colombiana.

Por otra parte, en relación con el bienestar pedagógico, Bustos y Montaño (2007), de la Universidad Pedagógica Nacional de Colombia, realizaron un informe acerca del bienestar en el aula, donde abordaron la temática sobre qué hace agradable o desagradable la permanencia de los estudiantes en la universidad, para ello, utilizaron un enfoque cualitativo etnográfico, para estudiar el fenómeno en estudiantes de los últimos semestres de Psicología y Pedagogía. A través de este proceso investigativo, concluyen que existen factores que posibilitan el bienestar subjetivo. Dentro de estos se encuentran la utilización de diversas estrategias didácticas que propician el trabajo en equipo y cooperativo entre los estudiantes.

Teniendo en cuenta los hallazgos de las anteriores investigaciones, se reafirma la idea de que la diversidad cultural es un fenómeno presente en la escuela y que a su vez, está determinando la forma de interacción de los estudiantes, influyendo directamente en su bienestar, puesto que este último es susceptible a cualquier condición del contexto.

De esta manera, se han venido adelantando algunas observaciones en la Institución Educativa Las Américas de Buenaventura, Valle del cauca, Colombia, la cual es un establecimiento de carácter oficial, que atiende alumnos procedentes de diferentes partes del país y de diversos grupos étnicos, como afrocolombianos, indígenas y mestizos, lo que hace que en ella se dé una amalgama de diferentes culturas. Así mismo, se ha venido reflexionando sobre los modos de interacción de estas formas culturales presentes en este contexto, ya que, se evidencia que entre los estudiantes surgen comentarios donde clasifican de bueno o malo, bonito o feo las formas de ser o los rasgos físicos que caracterizan cada etnia, generando situaciones de rechazo mutuo. Por otro lado, se observa que especialmente los estudiantes indígenas se aíslan, son poco expresivos de sus ideas y sentimientos y presentan un alto índice de deserción escolar. Para finalizar, se percibe entre los diferentes grupos, principalmente, entre los afros y los mestizos, que se dan formas de superposición entre sí, dando lugar a la conformación de subgrupos.

Estos acontecimientos que suceden en la cotidianidad de la institución, ponen de manifiesto la necesidad de intentar comprender la razón por la cual se están presentando estas situaciones y cuáles son las estrategias que ha venido adelantando la institución educativa frente a dicho fenómeno. Para ello, se estima conveniente abordar dicha problemática a través de la siguiente pregunta.

¿Cómo son las formas de interacción de los y las estudiantes paralelas al bienestar subjetivo, en un contexto escolar con diversidad étnica y cultural como lo es la Institución Educativa las Américas, ubicada en la ciudad de Buenaventura, Valle del cauca, Colombia? y ¿cuáles son las alternativas con que cuenta la institución para garantizar el bienestar pedagógico del estudiantado en un contexto escolar de diversidad e identidades propias?

\section{Metodología}

\section{Tipo de estudio}

La presente investigación se realizó con la metodología cualitativa, que como plantea Strauss, A., \& Corbin, J. (2002), puede tratarse de investigaciones sobre la vida de la gente, las experiencias vividas, los comportamientos, emociones y sentimientos, así como el funcionamiento organizacional, los movimientos sociales, los fenómenos culturales y la interacción entre las naciones.

Esta investigación fue guiada por la metodología cualitativa de tipo fenomenológico, que ayudó a acercarse al objeto de estudio, a partir de la experiencia concreta del grupo con 
el cual se trabajó, describiéndolo y analizándolo. En este caso, el fenómeno fue las formas de interacción de los y las estudiantes y su influencia en el bienestar subjetivo, en un contexto escolar con diversidad étnica y cultural, donde estos, a través de la narración de sus vivencias, permitieron una comprensión de las estructuras esenciales de los diferentes elementos que conforman el fenómeno abordado.

La fenomenología, de acuerdo con Martínez (1997), es el estudio de los fenómenos tal como son experimentados, vividos y percibidos por los seres humanos. Son realidades cuya naturaleza y estructura peculiar solo pueden ser captadas desde el marco de referencia interno del sujeto que las vive y experimenta. Dicho de otra manera, Colás citada por Buendía (1997), explica que la fenomenología plantea estudiar el significado de la experiencia humana, enfatizando la vuelta a la reflexión e intuición para describir y clarificar la experiencia tal como ella es vivida, y se configura como conciencia. En ese sentido, se interesa por las formas en que la gente experimenta su mundo, qué es lo significativo para ellos y cómo comprenderlo.

\section{Contexto, población y muestra}

La Institución Educativa Las Américas es un establecimiento de carácter oficial, que atiende una población de 2350 estudiantes pertenecientes a los estratos 1 y 2 , repartidos en sus tres sedes. Ofrece servicios educativos desde el preescolar hasta la media vocacional, con un énfasis académico en gestión empresarial. La muestra tomada, fue de 20 estudiantes, hombres y mujeres, con edades comprendidas entre los 11 y 19 años, vinculados a la educación básica y media. Para la determinación de dicha muestra se estableció como criterio la representación de cada etnia (afrocolombianos, mestizos e indígenas).

De esta manera se garantizó una participación de los estudiantes con ascendencias culturales distintas que interactúan en la institución.
Estos suministraron información valiosa acerca de sus procesos de interacción, lo cual permitió reconocer cómo esta incide en su bienestar subjetivo y académico. Así mismo, se eligieron los sujetos, luego de observar situaciones que se presentan en algunos de ellos por cuestiones de raza o procedencia, a quienes se les invitó a participar en la investigación, previa socialización de los fines del proyecto, asegurar la confidencialidad en la información y contar con su disponibilidad para participar, y consentimiento de los padres para el caso de los y las estudiantes menores de edad y con el debido permiso de los directivos de la institución.

\section{Instrumentos y procesamiento}

Los instrumentos para la recolección de la información fueron dos: la entrevista semiestructurada y la observación directa. Para el primero, se construyó una guía de 10 preguntas orientadoras, con las cuales se buscó reconocer elementos de las formas de interacción de los estudiantes con ascendencias étnicas y culturales distintas y el modo como estas afectan el bienestar de acuerdo con la percepción de cada integrante de la muestra escogida. Para el segundo instrumento, se implementó un plan en el cual se determinaron las fechas y se diseñó un formato para el registro detallado de cada observación.

Las entrevistas fueron grabadas y registradas en las notas de campo, previo consentimiento informado de los entrevistados. La ejecución de dichas entrevistas fue precedida por momentos de observación, tratando de reducir todo lo subjetivo del investigador, viendo todo lo dado y observando la variedad y complejidad de las partes que conformaban la realidad que se estudiaba. Finalmente, esta fase culminó con la elaboración del protocolo que consistió en la transcripción y el registro de los datos obtenidos en las conversaciones, haciendo una representación fenomenológica completa, natural, fiel y que reflejara el fenómeno tal como se presentó. 
Luego, se accedió a la delimitación de las categorías, mediante una exhaustiva revisión del protocolo que permitió comprender el posible significado que tenía cada unidad temática. Seguidamente, se procedió con la determinación del tema central de cada unidad temática y su expresión en el lenguaje científico. Fue una actividad creadora donde se trató de eliminar las repeticiones y redundancias en cada unidad, estableciendo su tema central mediante aclaraciones y elaboración de su significado. De esta manera, se llevó a cabo el proceso de categorización y subcategorización conceptual que facilitó la reducción de todas las categorías; que fueron apoyadas por la expresión textual de los entrevistados. Todo este procedimiento favoreció el trabajo de análisis de resultados.

\section{Resultados}

Con el objeto de dar respuesta a los objetivos propuestos en la presente investigación y tras el proceso de codificación de datos, se constituyeron tres categorías, a saber: Formas de interacción paralelas al bienestar pedagógico, Interculturalidad, y Estrategias de interculturalidad institucionales para el bienestar pedagógico, con las que se hizo el análisis apoyado en los fragmentos textuales suministrados por los informantes.

En la institución educativa, a través del reporte que hicieron los informantes, se perciben diversas formas de interacción entre sus miembros, marcados por el componente étnico y cultural de las etnias que hacen presencia en la institución, entre ellas, la afrocolombiana, que ocupa el primer puesto en número de sujetos, ya que esta zona del país es la región donde más población negra existe en Colombia, seguida por la cultura mestiza, constituida por hijos e hijas de inmigrantes del interior del país, llegados a esta zona y por miembros de la raza indígena, que ancestralmente ha ocupado este territorio. Situación tal, que ha favorecido que se hayan venido dando formas propias de interacción y procesos de mestizaje entre sí.
Dichas circunstancias habrían venido dando formas propias de interacción, las cuales han incidido positiva o negativamente en el bienestar pedagógico de los estudiantes del plantel. Es así como; la mayoría de los entrevistados reconocen que estudiar con personas de otras etnias ha favorecido sus procesos personales, en cuanto al afianzamiento de la identidad, mejoramiento de la autoestima y procesos de socialización, entre otros.

De igual manera, han podido adquirir nuevos aprendizajes de las otras expresiones culturales como la lengua, la manera de relacionarse y de ver el mundo, que se evidencia cuando dicen. “...en la relación, estás diciendo que con otros compañeros conoces nuevos términos, nuevas ideas y que eso te ha dado luces para tu proyecto y tu proyección académica en el futuro".

Los estudiantes indígenas, por su parte, reconocen que los docentes de la institución y sus compañeros les brindan confianza, seguridad, acogida, dándoles una buena enseñanza, y al estudiar con otros y otras, tienen la posibilidad de adquirir más y nuevos aprendizajes, que si estudian solo entre personas de la misma raza.

Se evidencia que los estudiantes de la etnia indígena de la institución, en su mayoría, manifiestan su deseo de superación, haciendo uso de sus capacidades personales, las que le facilitan la interacción con los demás compañeros y compañeras. "Me he sentido muy bien, quiero terminar mi curso y ser una buena estudiante. Me he relacionado bien, no he peleado, no he buscado problemas desde que era niña". Así mismo, se observa que han podido ir estableciendo relaciones afectivas entre ellos, valoradas como positivas, en cuanto han sido un apoyo en sus estudios.

También argumentan los entrevistados que se sienten bien al relacionarse con estudiantes de otras etnias, ya que, en el caso de los afros, dice uno de las colaboradores, son buena compañía, los mejores amigos, que han aprendido 


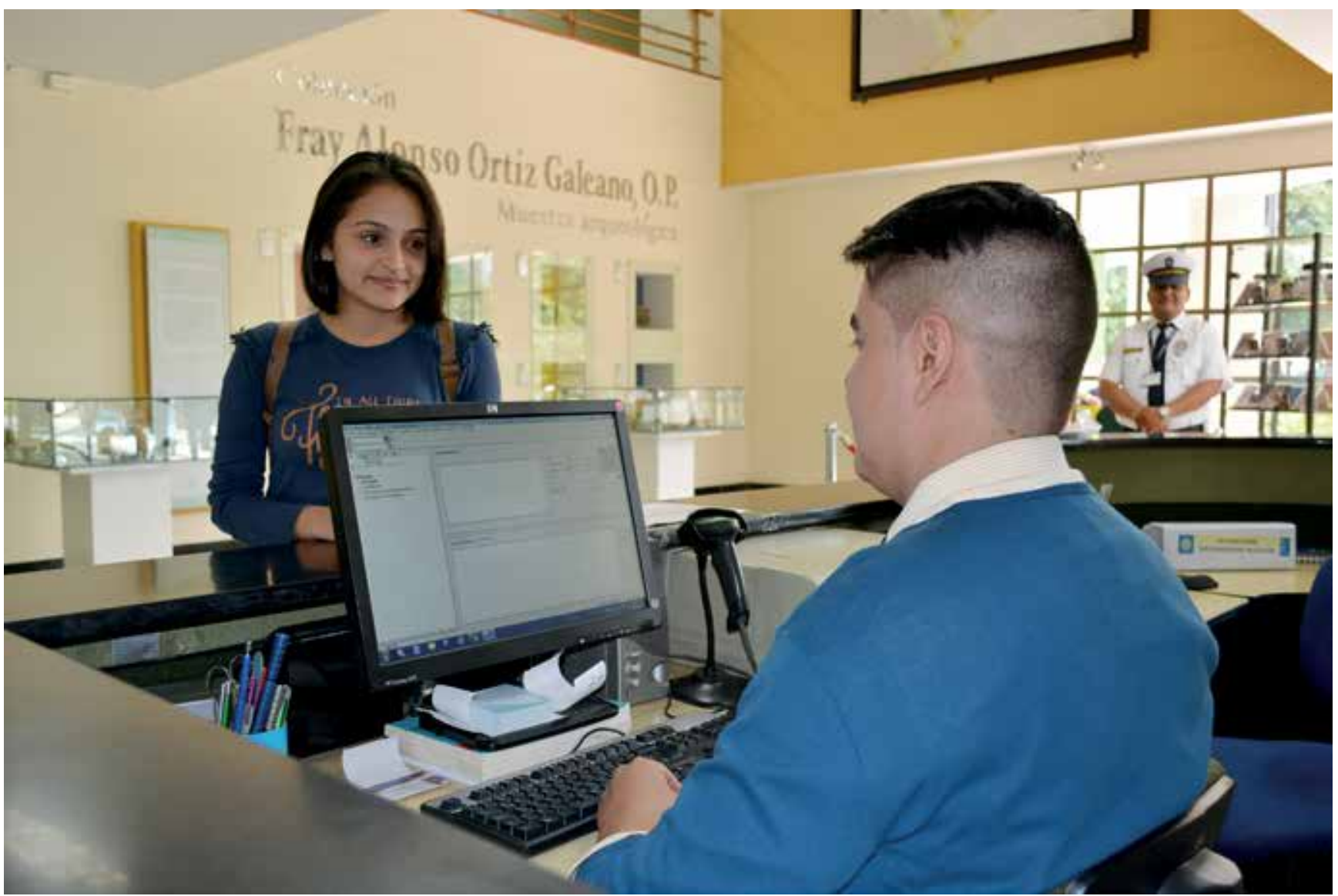

de sus raíces culturales, lugares de procedencia, forma de hablar y de sus comportamientos.

Se percibe además, que existen redes de apoyo entre ellos, lo cual les permite ir venciendo sus dificultades, teniendo en cuenta que tratan de animarse y apoyarse mutuamente, sirviendo de motivadores para el desarrollo de las actividades académicas, de modo que su ser minoría étnica y al encontrarse en un entorno diferente al suyo, no afecte su personalidad y su desempeño académico.

Los sujetos reconocen que la interacción con otros estudiantes les posibilita interactuar con otras formas de pensamiento, con otras capacidades, las cuales se emplean en el trabajo colaborativo y el diálogo de saberes, para la obtención de logros tanto personales como grupales. "...sí, la verdad sí, porque ellos tiene diferentes formas de pensar y diferentes capacidades, cada persona tienen diferentes capaci- dades, si todos juntamos nuestras capacidades, todos haríamos un mejor trabajo".

No obstante, a lo expuesto anteriormente, los sujetos entrevistados reportan además, que en la interacción con compañeros y compañeras de otras razas, han experimentado diversas situaciones que en algunos casos pudieron haber afectado su bienestar subjetivo y, por consiguiente, su proceso pedagógico en la institución educativa, ya que se han dado situaciones de rechazo y racismo entre unos y otros, que en ocasiones han generado sentimientos de inferioridad, malestar y deseo de abandonar el colegio.

También aportan que en el pasado han experimentado situaciones que en ocasiones generan choque entre los estudiantes, por cuestiones culturales, pudiendo llegar a interferir en el bienestar en el aula, causando sentimientos de rabia, rechazo, aislamiento social y resenti- 
miento, como respuesta a experiencias traumáticas vividas en el pasado.

Algunos alumnos reportan haber sido objeto de burlas, por pertenecer a la etnia indígena y tener una lengua diferente y al dificultárseles la pronunciación correcta de algunas palabras en castellano, situación que genera malestar, llevando en ocasiones a confrontaciones entre ellos. "Mis compañeros se burlan porque yo soy "cholo" y hablo diferente, porque tengo otra lengua y porque se me dificultan algunas palabras en español. Eso me hace sentir mal, por eso peleo, pero uno tiene que seguir adelante".

Expresan, además, que un número significativo de estudiantes, tanto indígenas como afrodescendientes se muestran aislados y retraídos, en la interacción con los demás y en la realización de algunas actividades académicas, situación que se visualiza con mayor frecuencia entre las alumnas indígenas, lo que hace inferir que tal comportamiento puede obedecer a costumbres culturales, ya que en sus comunidades ellas se asocian más a funciones domésticas, agropecuarias y al cuidado de los hijos, no tienen casi acceso a la relación con personas diferentes a las de su entorno y cultura.

Así mismo, podría decirse que su proceso de adaptación al nuevo medio, aún no se ha llevado a cabo completamente, aspecto que puede estar fortalecido al ser muchas de las familias víctimas del conflicto armado en sus regiones de origen, y a la situación de desplazamiento forzoso que han padecido algunas de ellas, venidas de zonas rurales de esta región, condición que puede hacerlos interactuar de forma tímida y poco expresiva y que además los haría vulnerables emocionalmente.

Del mismo modo, los participantes mencionaron que en ocasiones se presentan confrontaciones entre los estudiantes, especialmente entre negros y mestizos, al exaltar cada quien sus características físicas y tratar de ponerlas por encima de las de sus compañeros y compañeras de las otras etnias, argumentando que son en unos casos más atractivas, en otros más fuertes, ágiles para el baile, el deporte y con mayor resistencia física, situación que puede desencadenar en concepciones de aislamiento social, rechazo y racismo, lo que iría en detrimento del bienestar subjetivo y pedagógico.

De acuerdo con lo planteado hasta el momento, y siguiendo el análisis de la información suministrada, se puede abordar la interculturalidad como otro aspecto relevante y que está en directa relación con las formas de interacción, planteadas en la investigación.

La interculturalidad que se entiende como el proceso por el cual los seres humanos establecen relaciones, socializan y construyen las significaciones de la sociedad en la que conviven, es un aspecto que se visualiza en los reportes de los informantes y que se convirtió en un factor relevante en el proceso investigativo, en el que fueron surgiendo aspectos como el sentimiento de bienestar de los estudiantes al tener la posibilidad de estudiar con compañeros y compañeras de otras etnias, ya que entre ellos se identifican, se brindan acogida, respeto, apoyo mutuo, entre otros.

Del mismo modo, se puede decir que para algunas de las diferentes etnias, sus características de personalidad les han ayudado a interactuar más fácilmente con sus compañeros de otras razas, al estar en un mismo contexto educativo. Es por ello que, los sujetos reconocen que al relacionarse con otras razas no afectan su bienestar, sino que por el contrario, se convierte en una ventaja y una posibilidad para conocer y valorar más a los otros que son considerados como diferentes, desde el respeto mutuo, la colaboración, llegando a demostrar afectos entre sí, aspectos que les generan sentimiento de bienestar, lo que se evidencia cuando manifiestan:

La verdad, relacionarme con otras razas, esto no nos afecta a nosotros porque no tiene nada que 


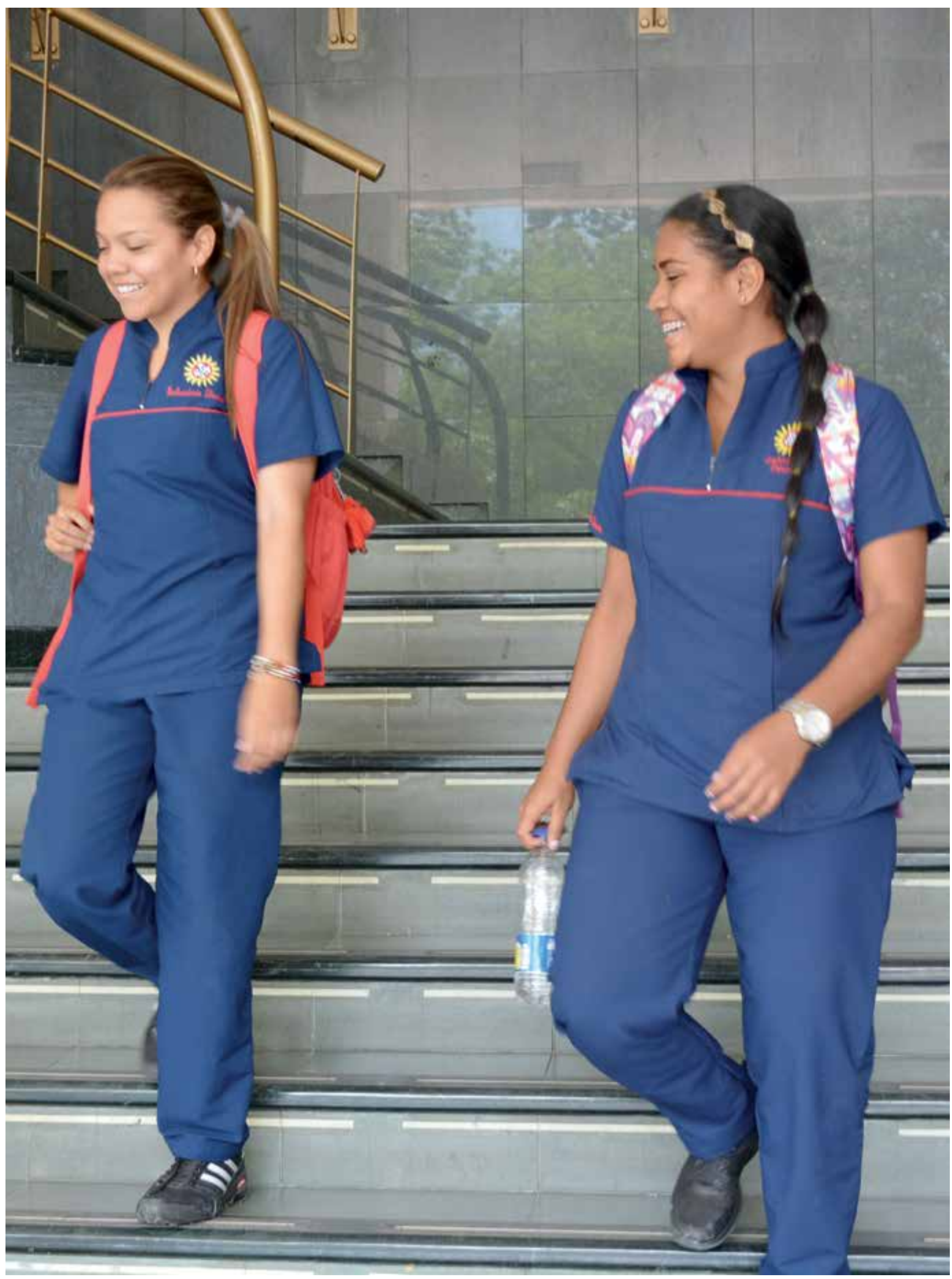


ver los diferentes tipos de raza o de etnia, ya que con respeto y una colaboración entre todos podemos tener un afecto y una buena relación, y la verdad, yo me ha sentido muy bien aquí porque no ha habido ni racismo, ni nada de eso.

Luego, se reconoce la diversidad étnica y cultural que se da en la institución, ya que en ella confluyen estudiantes de la raza indígena, mestiza y afrocolombiana, dándose entre ellos relaciones de intercambio cultural, en condiciones de igualdad, lo que podría concebirse como unidad en medio de la diversidad.

Se resalta además, que los sujetos en cuestión están en la disposición de realizar sus actividades académicas a nivel grupal, con otros y otras de las diversas etnias, donde cada uno expone sus cualidades y destrezas personales al servicio de lo grupal, y así obtener nuevos aprendizajes. "Si por ejemplo trabajamos en grupo, podemos integrar apoyando a las demás personas, en dibujo. A mí me gusta hacer dibujo también. Aprender el idioma y aprender a respetar el color de ellos".

De igual forma, algunos estudiantes manifestaron sentir que prefieren relacionarse con personas de las otras etnias, sin distinción alguna y expresan que no les gustaría estudiar solo con los de su raza, ya que esto les restaría oportunidades de aprendizaje "...me relaciono más con mi amiga Patricia que es afrocolombiana, me relaciono bien, no me importa lo que sea, si es negra o blanca".

No obstante a lo anterior, los integrantes de la muestra de estudio manifestaron que en algunos momentos de sus vidas llegaron a tener sentimientos y expresiones de tipo racista hacia los compañeros de otras etnias, producto de situaciones de este tipo por las que atravesaron en su infancia; situación que según ellos han afectado su proceso académico y el establecimiento de relaciones armónicas entre sí. Sin embargo, afirman que en la actualidad han aprendido a convivir y reconocer que todos y todas son personas iguales y que conviven en medio de la diversidad cultural, lo que enriquece sus experiencias vitales.

Hasta ahora bien, aunque la verdad, yo tengo que decir la verdad, yo era racista, cuando tenía unos doce, trece o catorce años, no me gustaba relacionarme con personas mestizas y la vedad, tampoco con indígenas, pero gracias a Dios, ahora ya he entendido que hay diversidad de culturas y que uno debe aprender de cada uno algo nuevo.

Algunos sujetos procedentes de otros lugares del país expresan que al llegar a estas tierras sintieron extrañeza, situación que fue disminuyendo al encontrar acogida, y formalidad, cosa que hizo cambiar el imaginario que traía sobre los habitantes de este territorio.

Pues la verdad me he sentido muy bien, al principio cuando llegué era algo extraño, pero la gente fue muy formal conmigo, nunca me aislaron porque yo fuera blanca, la verdad fueron muy bien conmigo, me acogieron bien. La verdad no he tenido dificultades con ninguno, y con todos me relaciono bien, trato a todas las personas de la misma manera.

Tras la descripción de las diversas situaciones que experimentan los estudiantes en sus relaciones interpersonales con los compañeros y compañeras de otras etnias en la Institución Educativa, las cuales según los entrevistados, en ocasiones favorece su bienestar subjetivo y en otras lo dificulta, se consideró conveniente analizar qué acciones o estrategias adelanta o podría implementar la Institución a fin de que sus miembros gocen de una adecuada interacción, para poder obtener un buen desempeño personal y académico, y llegar a configurar las estrategias de interculturalidad institucionales para el bienestar pedagógico en una tercera categoría de análisis en la investigación.

Los participantes de la investigación en su totalidad reconocieron que la Institución Educativa Las Américas brinda acogida a todas las personas sin distinción de raza, estrato social, orientación sexual, edad o apariencia física, lo 
que la constituye en un centro educativo regido por los índices de inclusión, donde cada uno de sus miembros puede ejercer su libre derecho de la personalidad, siempre y cuando esto no vaya en detrimento de las personas que la integran y de las normas institucionales.

Del mismo modo, reconocen que existe acompañamiento por parte de los directivos y los docentes para los estudiantes que ingresan a la Institución, brindándoles apoyo, comprensión, aspectos que han favorecido su bienestar. "Los profesores me han enseñado bien, me han explicado, han favorecido mi bienestar".

Así mismo, los estudiantes advirtieron que la Institución podría generar más espacios de aprendizaje significativos, frente a la relación interétnica, a través de encuentros de reflexión, a los cuales se puede hacer invitación a líderes y lideresas de la comunidad que pertenezcan a las diferentes etnias, con el fin de que compar- tan sus experiencias y saberes con los estudiantes, de modo que esto ayude a que se genere el diálogo intercultural en el plantel.

También, consideran conveniente que el Instituto adecúe su pedagogía, brindando una educación de calidad, que fortalezca los valores como el respeto, la tolerancia y la aceptación de lo diferente, teniendo en cuenta los aspectos étnicos, al igual que las celebraciones que se realizan en la Institución, como el día de la mujer, festividades nacionales e institucionales, así como los intercambios deportivos y la semana de la afrocolombianidad, donde además de resaltar los valores y tradiciones culturales del pueblo afrodescendiente, se tiene en cuenta y reconoce el aporte de las demás culturas en la construcción de la biodiversidad del país; así como potenciar las cualidades de cada uno de sus miembros. "... pues como que estar pendiente de los alumnos, realizar actividades,

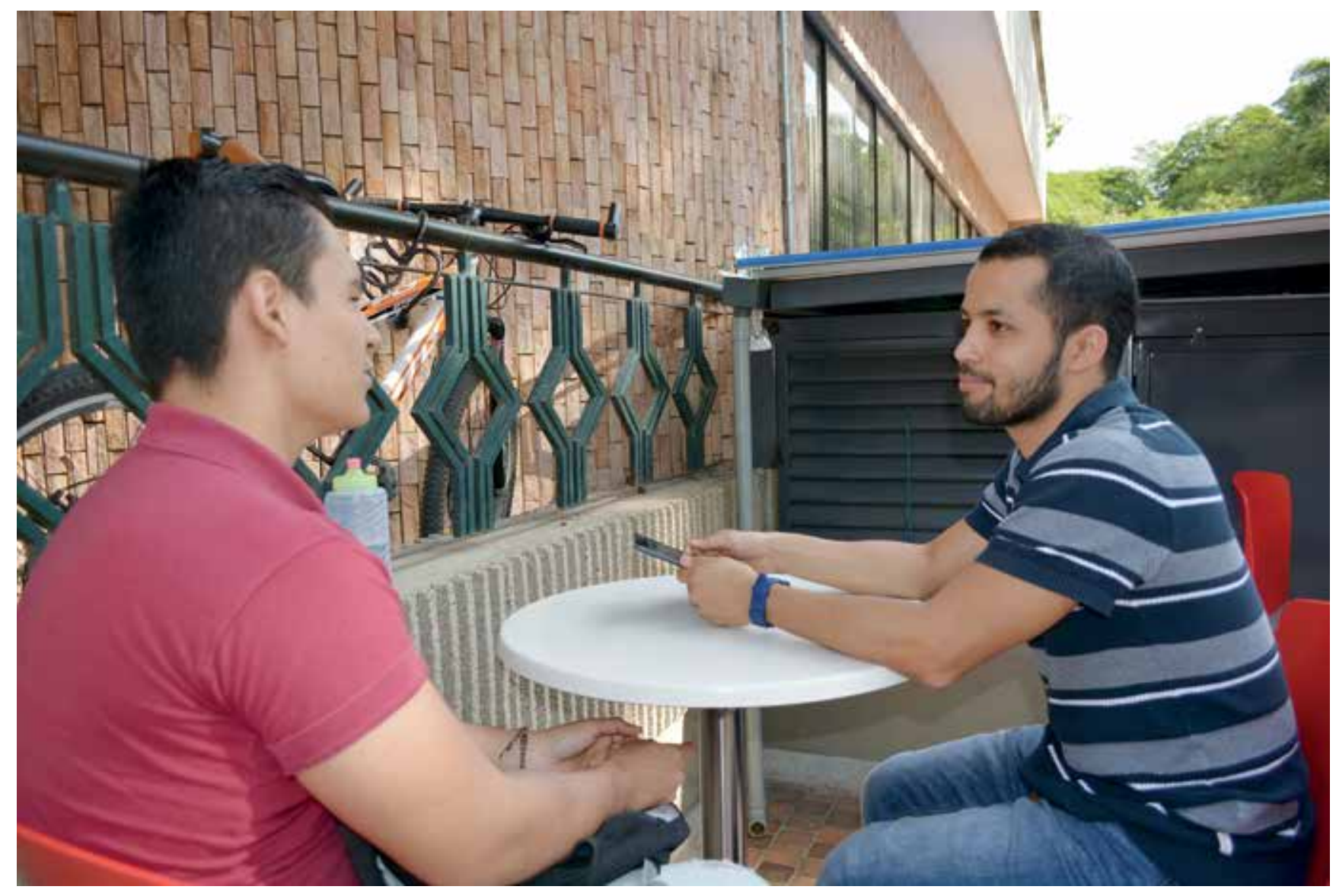


adecuar las enseñanzas pedagógicas, dependiendo de las capacidades de cada cual".

También se debe continuar favoreciendo el respeto mutuo, la aceptación de la diferencia y el trabajo colaborativo, entre otras, propiciando grupos de apoyo entre ellos, de modo que se brinde acompañamiento a los estudiantes que por su condición étnica, sexual, religiosa e ideológica o social, pudieran ser vulnerables a maltratos como burlas, rechazos, discriminación o aislamiento, situaciones que perjudicaría su bienestar en la Institución. “Hay unos que porque vienen de desplazamientos, entonces, pueden afectar la parte emocional, pienso que puede ser uno de esos factores".

Los entrevistados consideraron, además, que es pertinente que la Institución adecúe los espacios físicos, de modo que favorezcan la interacción entre sus miembros, ya que carece de escenarios deportivos, zonas verdes y espacios de recreación, los que facilitarían el encuentro entre los estudiantes, el compartir experiencias y vivencias, a fin de propiciar y fortalecer el diálogo de saberes y la interculturalidad. "Organizar un centro de recreación para que nos reunamos y nos recreemos entre todos".

Finalmente, se puede decir que la información relacionada en el presente texto, corresponde a los reportes textuales aportados por los colaboradores en la investigación; se reconoce además que en la recolección de los datos, aparecieron otros aspectos, los cuales no fueron tenidos en cuenta en el proceso de análisis, ya que carecían de relevancia, para el problema de investigación y para los objetivos planteados.

\section{Conclusiones}

Después de haber realizado esta investigación en la que se abordaron los temas de interculturalidad y el bienestar pedagógico de los estudiantes de la Institución Educativa Las Américas, de la ciudad de Buenaventura en el
Valle del Cauca, Colombia, se puede concluir que la Institución está marcada por la presencia de estudiantes afrocolombianos, mestizos e indígenas; evidenciando una diversidad étnica y cultural, propiciando que se manifiesten diversas formas de interacción afectando tanto positiva como negativamente su bienestar pedagógico.

En relación con los aspectos positivos, se advierte que estudiar con compañeros y compañeras de otras razas les ha ayudado a afianzar procesos personales, como su autonomía, autoestima e identidad cultural; al igual que los procesos de socialización y deseo de superación, al tiempo que se han generado relaciones afectivas entre ellos y se han ido constituyendo redes de apoyo.

De igual manera, se evidencia que en dicha interacción surgen nuevos aprendizajes desde el aporte que ofrece cada una de las etnias presentes en el plantel educativo, en cuanto a sus tradiciones ancestrales, lengua, formas de relacionarse y cosmovisión, entre otros aspectos, que respalda una nueva manera de visionar $y$ entender el mundo; desde el respeto a las diferencias, la tolerancia, el rechazo a todo tipo de discriminación, basándose en el fomento del trabajo colaborativo y el diálogo de saberes, aspectos entendidos como patrocinadores de la obtención de logros personales y colectivos.

Así mismo, se resalta que tanto los estudiantes de la Institución como los demás miembros de la comunidad educativa brindan acogida, acompañamiento a los nuevos individuos que llegan al centro educativo, especialmente a los procedentes de otras regiones. No obstante, lo anterior, se visualiza en la investigación que se han dado situaciones de rechazo y racismo, entre unos y otros estudiantes. Realidades que podrían haber afectado su bienestar personal, en los aspectos emocional y pedagógico, y en su desempeño académico, llevándolos en algunos casos a experimentar el deseo de desertar 


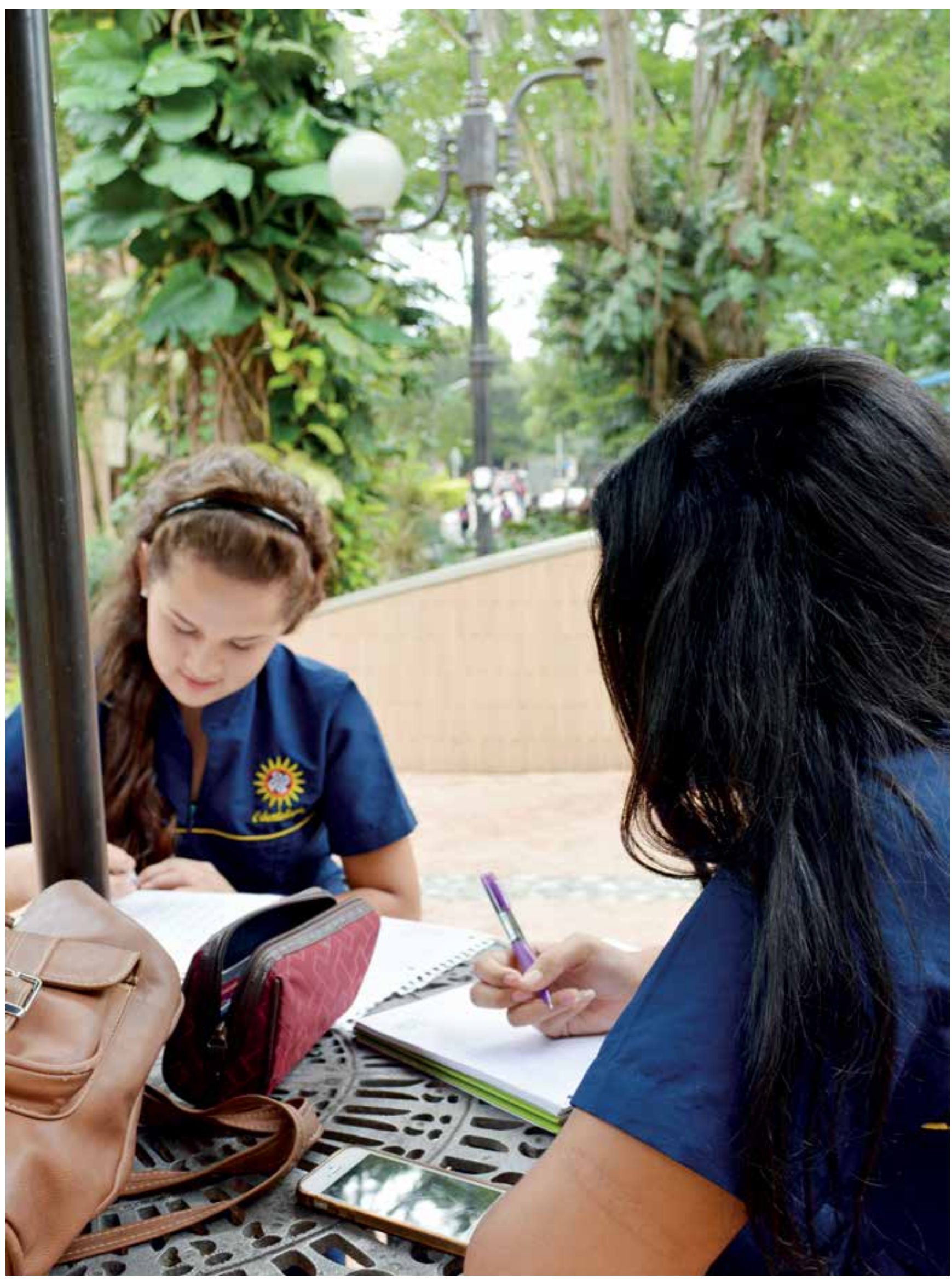


de la Institución como consecuencia de situaciones de choque cultural.

Se percibe además, que los estudiantes indígenas son quienes mayormente han sido víctimas de acoso o matoneo escolar, por parte de los demás estudiantes, por poseer manifestaciones culturales diferentes, ser víctimas del conflicto armado y desplazamiento forzado de sus lugares de origen; situaciones que los llevan en ocasiones al aislamiento social, de las cuales puede inferirse que en algunos de ellos no se ha dado un adecuado proceso de adaptación al nuevo entorno, circunstancias que habrían afectado el óptimo desarrollo de su proceso formativo.

Así mismo, se reconoce que el rechazo y racismo vividos en el pasado, pudieron incidir en la manera de relacionarse entre sí e incidir directamente en su desempeño académico. Sin embargo, se reconoce que mediante el compartir y al relacionarse con sujetos de otros grupos étnicos, pudieron ir venciendo prejuicios y rompiendo paradigmas, llegando a reconocer que todos y todas son seres humanos iguales, dotados de capacidades y cualidades, visión que les sirve para reconocer la riqueza de la diversidad étnica y cultural para una sana convivencia social, a partir de relaciones igualitarias e incluyentes en un espacio compartido.

En cuanto a las estrategias que adelanta la Institución para garantizar que sus miembros mantengan un estado óptimo de bienestar, se puede destacar que "Las Américas" es una institución incluyente, donde se brinda acogida y acompañamiento a los estudiantes oriundos de otras regiones del país $y$, por ende, de otras culturas. Del mismo modo, se potencia el libre desarrollo de la personalidad y en cuanto a sus miembros, se les permite manifestar sus expresiones culturales, desde el respeto, la tolerancia y el apoyo mutuo, entre otros, siempre que se acaten las normas institucionales, a fin de que su proceso adaptativo sea una manera más efectiva.
Sin embargo, se reconoce que el Instituto podría generar mayores espacios de aprendizaje interétnico, desde el fomento del diálogo de saberes, donde los miembros de los diferentes grupos puedan compartir sus vivencias y riquezas ancestrales. En este sentido, invitar a líderes y lideresas de diferentes etnias, de modo que compartan sus vivencias y se genere un espacio de aprendizaje en el plantel educativo y generen motivación en los estudiantes, hacia el logro de sus ideales.

Se considera importante además, que la Institución evalúe y reestructure su Proyecto Educativo Institucional, atendiendo las necesidades y características interétnicas de sus miembros, no solo desde la implementación de la Cátedra de Estudios Afrocolombianos, estipulada por el Ministerio de Educación Nacional de Colombia, bajo el Decreto 1122 de 1988, sino desde el abordaje de los saberes de los grupos mestizos e indígenas que hacen presencia en la ciudad; fomentando así la concepción de la $\mathrm{Na}$ ción como país pluriétnico y multicultural.

En razón a lo anterior, el plantel debe continuar conservando y fortaleciendo la solidaridad, la confraternidad y la capacidad de acogida, consideradas valores ancestrales de las comunidades negras, entre los sujetos que conforman la comunidad educativa, con el propósito de constituirse en el soporte entre sus integrantes. Así mismo, se estima conveniente la creación de un departamento de bienestar pedagógico, con un enfoque de inclusión e interculturalidad, desde donde se generen programas y proyectos dedicados al fortalecimiento de la identidad y valoración de la diversidad.

Otra alternativa que ayudaría a mejorar el bienestar académico en el Instituto, es adecuar espacios físicos como escenarios deportivos y zonas verdes, donde se fomente la interacción, la retroalimentación de experiencias y el diálogo de saberes. 


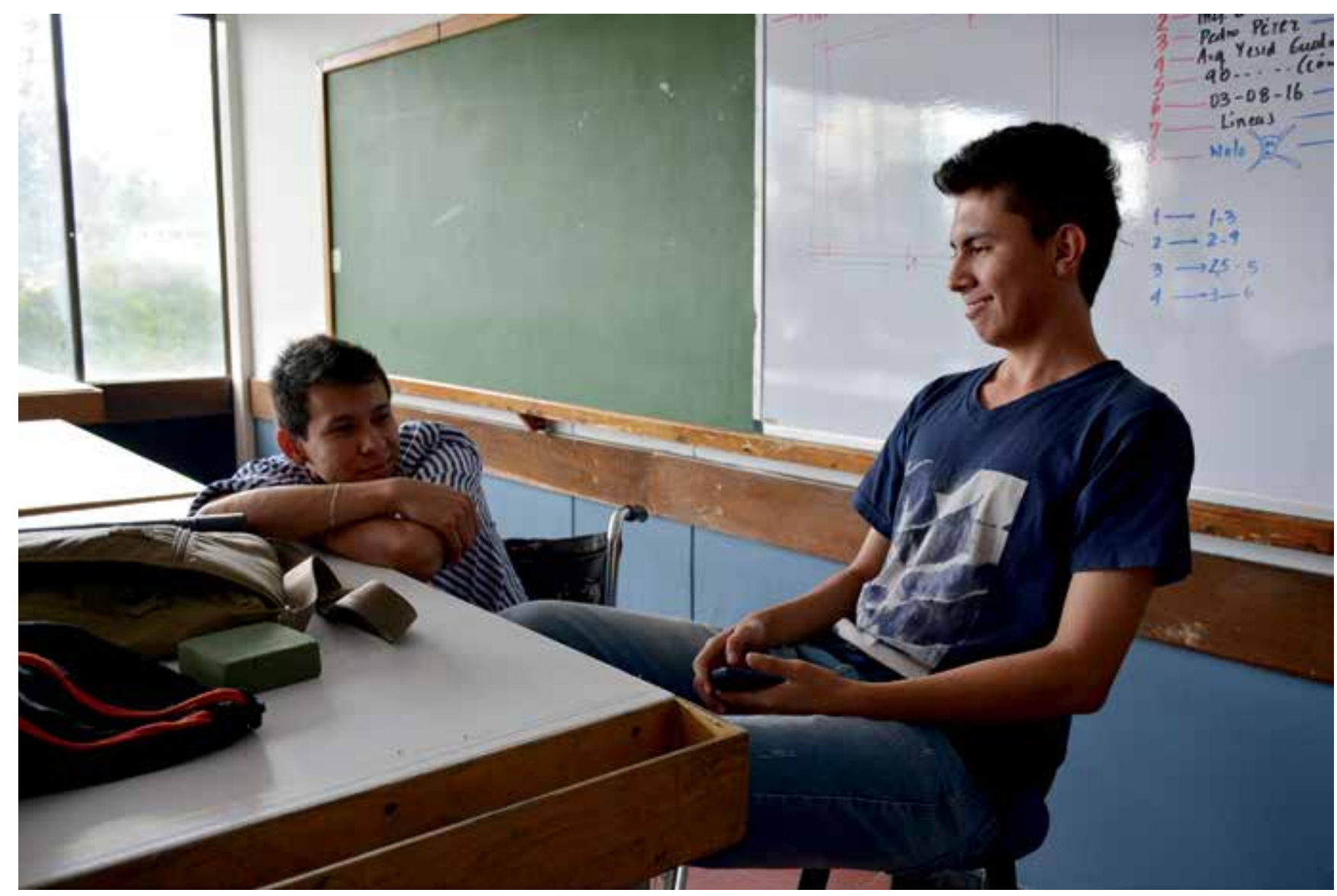

En relación con los aspectos que limitaron la investigación, se reconoce que algunos sujetos de la etnia indígena se mostraron tímidos y poco expresivos al momento de la entrevista, lo que podría estar relacionado con sus características culturales. También, la situación de violencia que se presenta en la ciudad y especialmente en los sectores donde el plantel tiene sus sedes, dificultó que se pudiera llegar a un mayor número de participantes, ya que algunos estudiantes se abstienen de brindar información por situaciones de zozobra y temor en que viven.

Para finalizar, se puede decir que en el transcurso de la investigación fueron surgiendo otros aspectos que podrían ser objeto de estudio en futuros trabajos, tales como: ¿Cuál es el impacto de la violencia y el desplazamiento forzado en el bienestar pedagógico de los estudiantes de las instituciones oficiales de la ciudad? ¿Cómo inciden las tradiciones culturales de los estudiantes de la etnia indígena en su bienestar pedagógico? ¿Qué estrategias de etnoeducación se pueden implementar en la Institución Educativa, por motivo de la alta diversidad étnica y cultural? ¿Qué características debe tener el Proyecto Educativo Institucional - PEI de la Institución Educativa, teniendo en cuenta que sus estudiantes provienen de poblaciones vulnerables, afectadas por la violencia y la discriminación racial? ¿Qué procedimientos y estrategias debe implementar la Institución Educativa para conservar el acervo cultural de cada grupo étnico de estudiantes?

\section{Referencias}

Aguado, T. (2005). La educación intercultural en la práctica escolar. Investigación en el ámbito español. Universidad Nacional de Educación a Distancia.

Bustos, \& Montaño. (2007). Informe de investigación, el bienestar en el aula de clases. Universidad Pedagógica Nacional. 
Castro, C. (2009). Estudios sobre educación intercultural en Colombia: Tendencias y Perspectivas. Memorias, No. 10. Uninorte.

Conferencia Internacional de Educación. (2008). La educación inclusiva: el camino hacia el futuro.

De Pablos, J., \& González, G. (2012). El bienestar subjetivo y las emociones en la enseñanza. Revista de la Facultad de Ciencias de la Educación. Universidad de Sevilla.

Díaz, D., \& Rodríguez, R. (2006). Adaptación española de las escalas de bienestar psicológico. Revista Psicothe$m a, 3(18), 572-577$.

Florez, I. (2005). Identidad cultural y sentimiento de pertenencia a un espacio social: una discusión teórica. Revista la Palabra y el Hombre.

Hirmas, R. (2008). Educación y diversidad cultural: lecciones desde la práctica innovadora en América Latina. Santiago de Chile, Chile: Pehuén.

Kottak. (1994). Antropología, una exploración de la diversidad humana. Madrid: McGraw-Hill.
Martínez, M. (1997). Comportamiento humano: nuevos métodos de investigación. México: Trillas.

Pino, D., \& Gallegos. (2011). Las teorías de la interacción social en los estudios sociológicos. Recuperado el 13 de febrero de 2015 de http://www.eumed.net/rev/ cccss/14/pbag.html.

Ritzer, G. (2003) Teoría sociológica clasica. Madrid: McGraw-Hill.

Säez. (2006). La educación intercultural. Revista de Educación, 339, 859-881.

Strauss, A., \& Corbin, J. (2002). Bases de la investigación cualitativa. Técnicas y procedimientos para desarrollar la teoría fundamentada. Medellín: Editorial Universidad de Antioquia.

Unesco. (2014). Enseñanza y aprendizaje: Lograr la calidad para todos. París, Francia: Ediciones Unesco.

Walsh. (2005). Interculturalidad, conocimientos y decolonialidad. Signo y Pensamiento, 24, 39-50. 